\title{
Fine values for urban coordination in spaces of new communities of Economic Housing
}

DOI: $10.21625 /$ archive.v1i1.138

\author{
Muhammad Yunus Fekry Amer ${ }^{1}$
}

${ }^{1}$ Assistant Teacher - Interior architecture and decoration Faculty of Fine Arts - South Valley University

\author{
Keywords \\ Urban Coordination - \\ Design Sites - Identity - \\ Ecology - Morphological \\ configuration of the city
}

\begin{abstract}
The idea of this research was developed as a result of the new direction of urban development taking place in The Arab Reupblic of Egypt along with the emergence of new cities that mark a new age in Egypt's modern history. This paper also highlights the importance of completing important national projects with the highest possible standards and least possible cost in order to satisfy the people's needs.

Egyptian artists have always excelled in the field of architecture as their creations are still present today and they all mark these architects' interaction with the natural environment in terms of the materials used. These characteristics are now a way to distinguish Egyptin artists because of the different analyses carried out for the modes of movement, the intersection of lines, shapes, light, colors, and consistency along with the various cultural values that contribute to the enrichment of Egyptian history.

There is a set of visual determinants and characteristics that are exclusive to every city, this, in turn, shows each city in its aesthetic form that distinguishes it from others. This is dependent on a group of environmental and design-based characteristics that are used when aesthetically designing a city. This is starting with its morphological model which is concerned with the overall aesthetic design of the city and ending with applying the values of the deisgn of urban coordination of sites (Landscape), which is concerned with the design of public spaces. A good design is one that applies all the visual and aesthetic determinants needed for their formation.

The concept of identity is considered one of those concepts that are hard to accurately explain as it's more of an ecological concept rather than a scientific one. Identity plays a leading role in the design of buildings that manage to reflect the environment which it's in, as it is considered the main criterion for measuring the success of the community. On that basis, the identities of buildings are developed as a result of employing specific elements. The built environment therefore is an effective means through which the community can confirm its identity and distinguish itself among other communities.
\end{abstract}

\section{The establishment of new communities:}

There are many motives behind the creation of the new cities, and these motives are economic, social or ideological and more motives may exist, including: redistributing citizens over the country, directing the urban growth of remote places, and trying to go beyond the narrow strip of the Nile Valley (1).

New cities have emerged and were set as an example of innovative way to highlight the relationship between humans and buildings, land, and development. This is what we aim to document along with the extent of benefits 
these new communities gained from urban development and the new aesthetic values and from presenting new aesthetic characteristics (2).

\section{Fine determinants of Urban Communities:}

There are a set of visual limitations that every city generally has in order to show that it has an aesthetic form that distinguishes it from other cities, depending on a variety of factors. This depends on a group of factors considered when designing a city starting with its morphological model that is concerned with the overall beauty of the city and ending with applying the values of the deisgn of urban coordination of sites (Landscape), which is concerned with the design of public spaces. A good design is one that applies all the visual and aesthetic determinants needed for their formation. This allows for the creation of buildings that are similar to those in European countries because they include all the necessary architectural considerations on different levels that cimpliemnt each other, those include urban coordination, urban design, and attentiveness to detail in order to fit the general aesthetic form. This is exactly what fails to take place in Egyptian cities as all the aforementioned steps and requirements are applied, but without considering aesthetic design. There are several things that are neglected, such as the study of visual dimensions or highlighting the importance of interior architecture even though they have serious psychological and physiological effects on the residents of these buildings and their vistors (3).

This research aims $t$ highlight the importance of creating an environment that is visually appealing by applying aesthetic values and urban coordination and development that the responsible architect depends on when designing the building internally in public spaces, this is done in order to beutify Egyptian cities. This is carried out by studying their forms and their relationship to the surrounding building elements, colors, and the design of streets in order to improve the visual image of the city. The design of the city should reflect its identity so that it could be on the same level of private projects that have high-quality buildings, but at a more economical level.

\section{Citizens' needs in new communities:}

Residential buildings represent the largest part of buildings in general in newer cities as well as open areas and different service structures. In his famous model in which he gradually arranged the aggregation of basic human needs, Abraham Maslow pointed out that each individual needs overlapping and interrelated priorities that he or she seeks to achieve and these can be arranged in the following points:

- The provision of material needs.

- Provide safety, security and protection.

- The provision of belonging to the environment and to achieve social networking

- Being autonomous

- The possibility of creativity and cognitive needs (4)

It is evident that the government and ministries that are specialized in architecture sought to establish residential buildings subsidized by the government. These were designed and implemented quickly but it resulted in the creation of superficial buildings that defy all developmental values. They represent architecture that is applied without thinking or innovating. There also buildings that with designs that do not match the requirements of the environment, and proved to fail for many reasons, such as they cause a defect in the urban environment as a result of disintegration of the fabric (5).

\section{Problems of open areas:}

- Cities have become cement forests devastating our natural environment making it void of green spaces

- Poor distribution of green areas

- The control of the mechanical movement on the formation of the urban fabric is considered to be worthy of the rights and needs of pedestrians

- The absence of humanitarian dimensions when designing open areas.

- Man-made constructions established on green areas

- Misuse of the open areas 


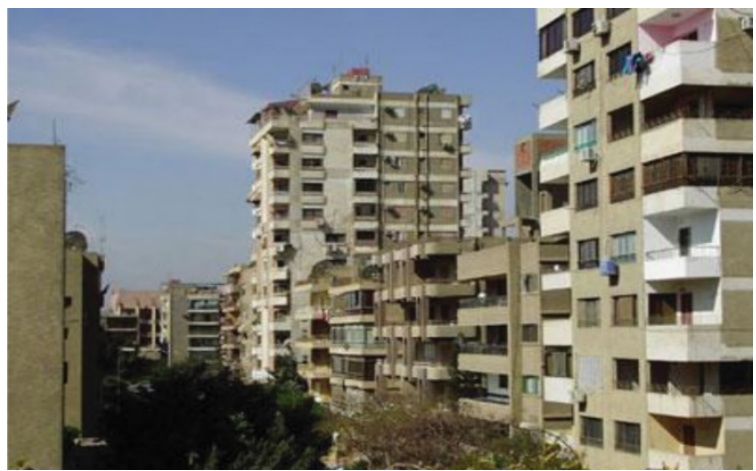

Figure (1) describes the cement forests of the city and the lack of respect for the green areas and privacy of the population along with the lack of interest in protecting public spaces and taking care of building fronts

\section{The causes of these problems:}

- The absence of a comprehensive thoughts to implement open area planning strategies at the national, regiobal and local levels.

- The absence of the overall concept of a network of open areas, resulting in poor distribution of sites that are not linked to each other.

- Lack of financial resources that allow the provision and maintenance of open areas.

- Increased population and structural density, high real estate value of the land.

- Neglect and deterioration of the existing few open areas and the lack of periodic maintenance. Lack of environmental awareness among visitors and users of the open areas and it's not maintained

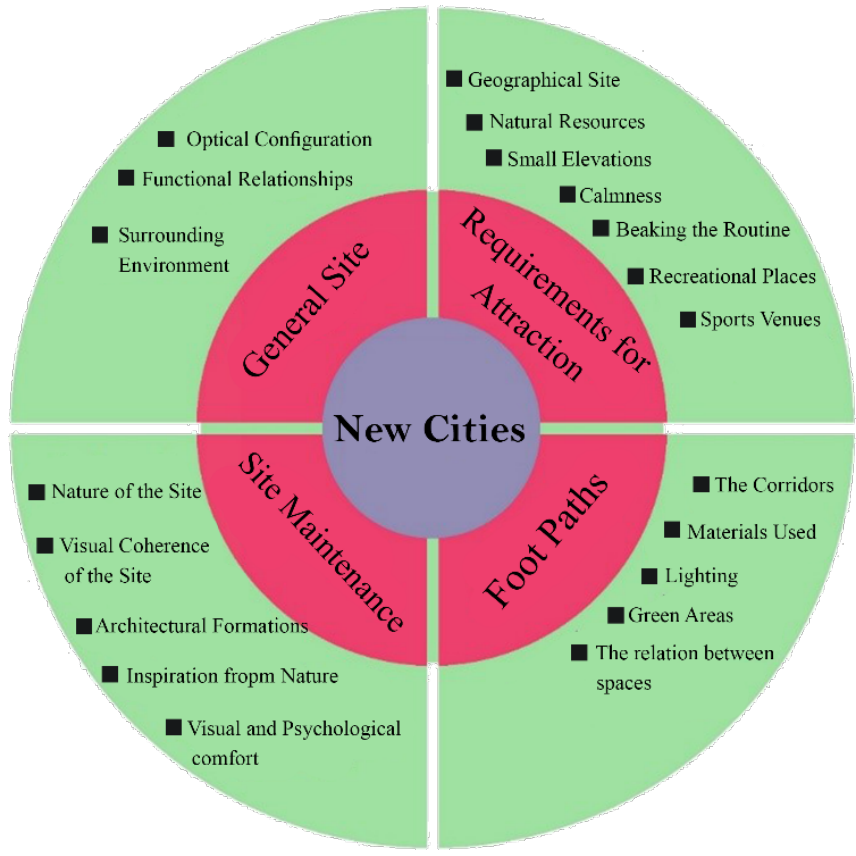

Figure 1 shows the layout of the point of attractions in new cities

\section{Ancient Egyptian Artist and its interaction with the environment:}

The ancient Egyptian artist interacted with and excelled in architecture as their creations are still present today and they all mark these architects' interaction with the natural environment in terms of the materials used. These characteristics are now a way to distinguish Egyptin artists because of the different analyses carried out for the modes of movement, the intersection of lines, shapes, light, colors, and consistency along with the various cultural values that contribute to the enrichment of Egyptian history (7).

An architect is always a true reflection of his or her environment in all its historical stages because he or she has become the architect that he or she currently is as a result of the interaction of environmental factors such as the climate, economy, society, education, history, and religion. The interior architecture 
of the environement comes as a result of the relationship between the natural environment and the design of the environement. This achieves compatibility between design and the surrounding environement and focuses on compatibility and harmony between the elements of design. This is in addition to trying to make full use of the sources of inspiration for natural objects through their internal construction and external characteristics to achieve creative design treatments. The task of the interior designer is to develop the principles and foundations, shape and design, and to be inspired by the natural elements to create a link between them and the external and internal designs.

Interior architecture plays an influential role in new architectural societies in terms of internal and external design as it provides the person with the suitable spaces and it deals with the natural and surrounding environements and the materials that are suitable in that particular time and place. It also plays a role in creating internal and external spaces that attracts people (8).

Environmental Design: A modern trend in the field of design emphasizes how to preserve the environment and create a link between the economy and beauty. The designer is the person who links the products at hand to elements of the ecosystem and thus reach a positive environment and not a negative one.

Organic Design: This refers to the integration of design with the properties of materials and ores while respecting the homogeneous relations between the shape, design and function of the interior space. This attempts visual communication and integration with the surrounding natural environment by studying its analysis of the organic elements of nature.

The following are the characteristics of living plants and animals so that organic design can be influenced by the natural envirnement:
1.Visual communication
2. Added (growth)
3. Texture
4. Link design to the natural environment
5. Merger
6. Unity and Integration
7. Motion
8. Flexibility
9. Optical Modulation
10. Dormancy
11. Cohesion
12. Repetition
13. Natural raw materials
14. Gradient
15. Overlap and connect
16. Colors
17. Impartiality
18. Containment (9)

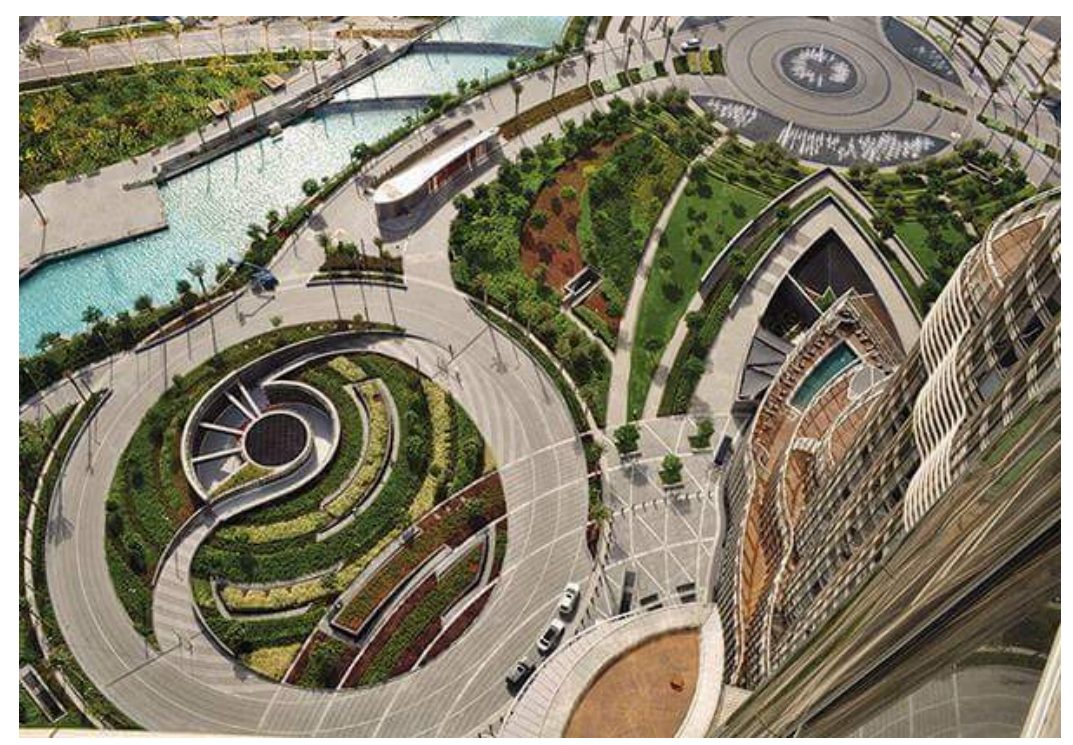

Figure (2) This innovative design illustrates the application of the thought of organic design in the open areas

\section{Inspiration from Nature}

Nature is a source of inspiration in arts and architecture and the designer is aware of the importance of being inspired by the elements of the natural environment in his work. This is important in order to establish the concept of the natural environment as a superior one over formation systems and design solutions through the extraction (unity - proportion - rhythm - raw materials - balance - dots - lines - spaces - shapes - texture - colors) from natural elements. This is manifested in interior architecture which draws on and borrows from elements of the surrunding 
natural environment. This achieves the compatibility between the form of design and function in order to reach the design that is both attractive, functional, and environmentally friendly (10).

\section{The factors of location and urban configuration:}

Every location has unique characteristics or a distinct personality that is formed based on its natural potential and functional importance on the level of the city or region in which it is located, as follows:

a. Natural possibilities: some of the locations have advantageous characteristics like differences in elevation, a mountaineous background, beaches, and green areas. They therefore need to be proportioned in a visually appealing way in order to be able to take advantage of them correctly and develop them.

b. The location of the given area in relation to the city: some places have unique locations within the city like in the center of the city, the borders of the city, city entrances, and a place that links all the traffic axes in the city. This gives them a functional importance and they have their own visual properties that have to be studied and developed, especially in visual aspects to achieve a balance between functional needs and aesthetic characteristics.

c. The urban configuration of the area: The follow-up of the spaces and the layout of their distribution gives a special character to the region and provides opportunities for visual coordination to raise the visual environment of those spaces. The formation of these spaces varies in size and proportions of spatial dimensions and architectural elements that define the entrances and exits, and the relationship of these spaces with the activities practiced within and around (11).

\section{Technological Factors:}

This factor includes several elements from one era to another and from one society to another and it consists of building materials and the techniques followed during construction along with scientific and technological methods. Building materials and construction methods affect the shape and structure of architectural spaces and this is evident in a new building if it reflects the magnitude of its development in its modern building materials, construction methods, and technological techniques. That is also evident when it comes to its large size along with its color and texture (12).

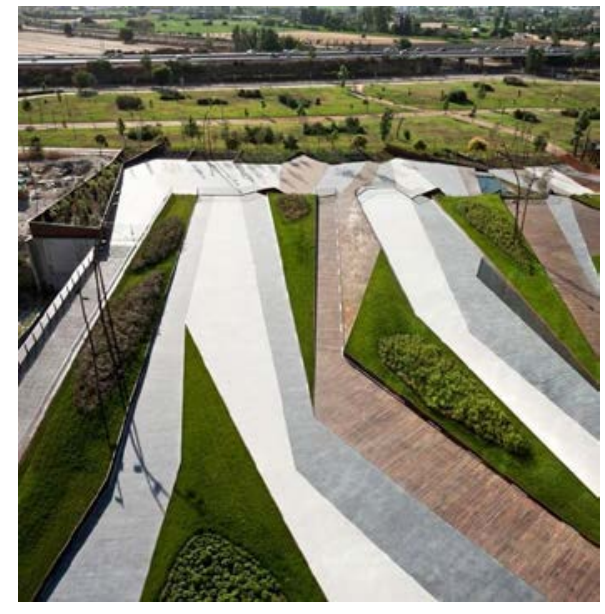

Figure (3) Shows us how we depend on modern materials and new thinking in design

\section{Role of Urban Coordination:}

The city has a very complex form, as its elements are overlapping and intertwined, and the realization of the city's distinct visual identity is through visual images that conform to artistic and aesthetic architecture along with functional, social, and cultural values on which urban planning is based on.

The role of urban planning is to recreate the visual identity of architecture using different ways such as the individual attempts that lean towards the concepts of unconcious beutification. Architecture in general is a series of visual sequences that cannot contracdict with personal concepts.

To activate the concept of integration between science of architecture, arts and aesthetics within the framework of an integrated design stemming from the concepts of civilization, culture and heritage. 
Encourage the spread of works of art in the urban spaces of the city provided that it represents a high level of thought and art and enhances the surrounding environment (13).

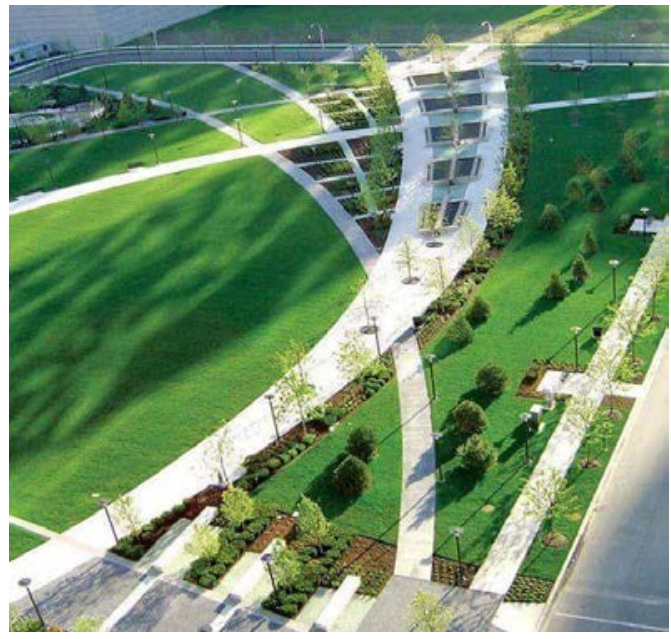

Figure (4) This is the design of one of the open areas between the units urban area were employed plants of different colors and artwork, and environmental and natural materials to create a unique visual spectacle.

\section{The design and coordination of external Sites:}

The coordination of sites aims to integrate the sophisticated environment that is coherent and therefore serves the needs and demands of humans that require a harmonious and balanced interaction together with nature in its various elements and to get out of the state of monotony in architecture and add excitement to the urban environment and to meet the desire of man to approach the natural components of the environment, which is his first interest.

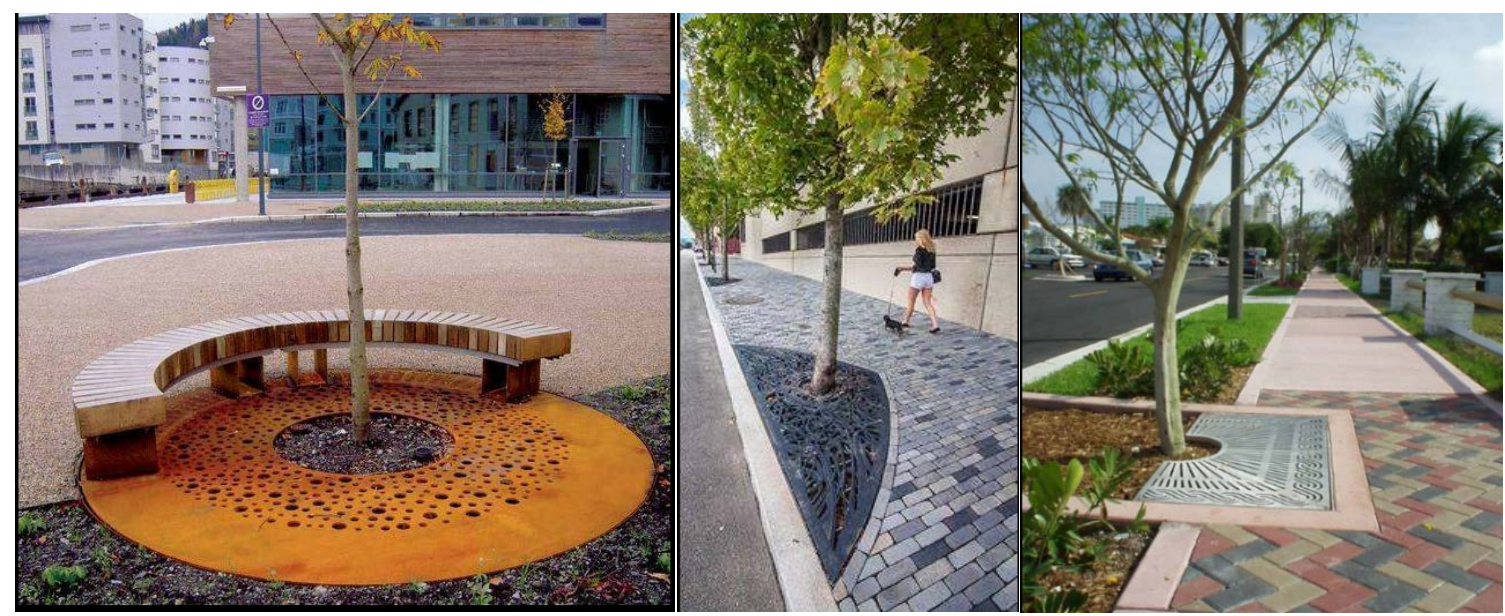

Figure (5 - 6 - 7) It is a range of different solutions in the coordination of external internet sites and the use of natural raw materials with the use of new possibilities and innovative design solutions.

\section{Planning and coordinating sites:}

It is the technical process of science (engineering, agricultural and planning) to design, coordinate and improve and beautify the elements of life which contributes to the environmental balancing process, a continuous process of endless creation of the site and format. The site planning and coordination processes are very similar to the design and coordination of an internal space consisting of floors, walls and ceilings (horizontal and vertical elements). The sites are of two types:

Natural Land Scape: are existing sites as innate nature without human intervention, but by the laws of the life cycle and their interactions with each other, all these natural sites have distinct features (Land scape character). 
Manmade Land scape: They are the sites that involve human intervention in the components and elements where humans removed some elements of the original site and added other ways or their own distinct style (14).

The objectives of planning and coordinating sites:

- $\quad$ Recreation and recuperation and convalescence and practice sports.

- Separation between buildings in crowded areas and provide privacy where required to do so.

- $\quad$ Provide places for children to play especially those living in apartments in high-rise buildings.

- Provide appropriate environmental atmosphere and provide certain protection from the sun or wind or noise or other air pollutants.

- Solve some problems, such as the protection of the hills and uplands of collapse.

- Solve of some problems on the city level, such as pollution, as well as city beautification and coordinate the streets, squares and so on.

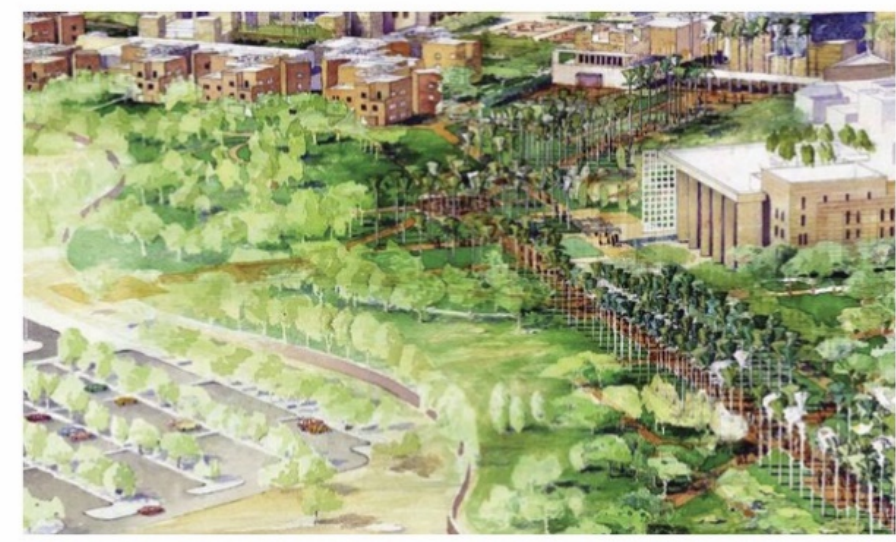

Figure (8) Coordination between different site in entertainment areas and parking facilities and residential buildings

\section{Classification of open spaces and levels:}

The network of open spaces is made up of two main elements which are open areas or spaces and connecting axes. The open areas in the city vary in size, level of service and degree of specialization, and these gradient levels must be commensurate with the population and needs of their services. Open areas can be classified into planning levels:

Linked open areas axes are classified as follows:

Green Belt

Axial Gardens

Environmental themes

Historical themes

Entertainment hubs

\section{Directed contemporary design:}

A trend that is in line with prevailing philosophical and intellectual ideas and does not adhere to the well-known rules of design. However, it follows a philosophical self that conforms to modernity, postmodernism and deconstruction, which usually requires the use of technological development and progress in construction methods (15).

\section{Fine and designed values and foundations for outdoor spaces:}

Although there are different approaches and ideas to the design visions of the regions and external spaces from one location to another due to many variables, there is a common design language of its uniqueness (scale, unity, coherence, proportion, balance, simplicity, repetition, diversification, Lighting and shade), which represent the foundations of the design of open areas.- Axes: the open area must be designed depending on the nature of the tracks within the major and minor axes and the relationship of that nature entrances and each axis is the beginning and the end. 
- The axes: The open area should be designed according to the nature of the paths within it from the main and secondary axes and the relation of that to the nature of the entrances and gradations, and that each axis has a beginning and an end

- Scale: The scale of items should be determined in proportion to the spatial space and reflect the nature of activity and behavioral patterns of users of the area.

- Unity and coherence: Site coordination should reflect unity and coherence through the intended repetition of formatting elements.

- Proportionality: All parts and components of the garden are balanced, taking into account the size, types and characteristics of plants and afforestation in order to conform to the nature of origin.

- Sovereignty and control: in the design of gardens, the recruitment and highlighting of elements and components of the coordination of the site is important in order to maximize the sovereignty of the establishment or highlight the unique value of the site.

- Simplicity: Selection of a limited number of types of elements in coordination with the location to avoid the crowded garden with trees or buildings for easy maintenance.

- The external character and appearance: Characteristic of the shape of the public park and each garden with its features that are formed by its establishment, which highlights its independent personality.

- Repetition and diversification: It is preferable to follow the repetition of some elements of the components of the garden so that there's a sequence without interruption to connect parts, but still taking into account the prevention of repetition so that it isn't boring

- Sequencing and widening: Arranging the elements of the coordination of the site so that it is seen in a visual sequence to achieve a harmonious format in one system.

- Colors and their gradients: careful study of the colors of plants and types of elements used and different materials and the gradients of colors to suit each other.

- Dissonance and compatibility: The plant units set together should be coherent so that the human eye can shift from one plant to another smoothly and without one overshadowing the others. As for dissonance it's prefered to be at the borders of a region to show the importance of one element of the composition.

- Lighting and shade: light and shade are important elements in landscaping, this is due to the method and style of its shape and distribution (16).

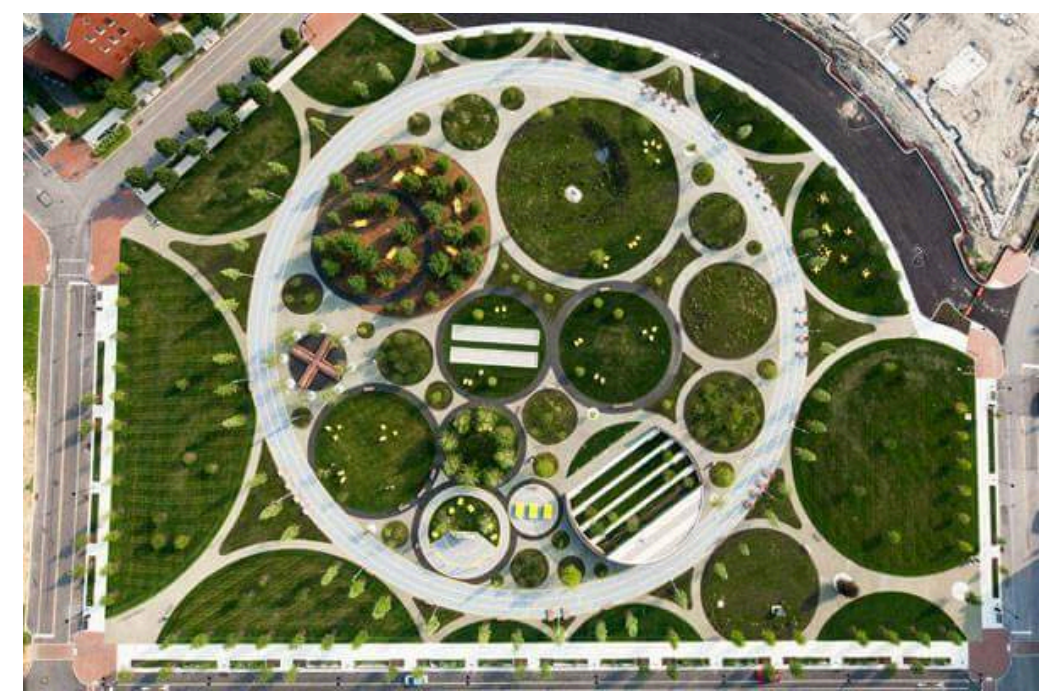

Figure (9) One of the open spaces between the residential area and has been taking into account the different values in the Fine Design

\section{The concept of identity:}

The concept of identity is one of the concepts in which we find it difficult to find a clear and specific definition. It is an ecological concept rather than a scientific concept.

Identity plays a key role in the design of the buildings that express the society (visual identity), which is the main criterion for measuring the extent of the success of the community. Therefore, it is possible to say that the identity 
of buildings arises as a result of the employment of specific elements. The community must emphasize its identity and distinguish it among other societies (17).

It's obvious that the existance of buildings and the identity of a community is of utmost importance, and the interfaces of the architectural monuments existing in a country or a city express the identity of that place. Identity is a crystallized concept in the structure through the shape and characteristics.

The spatial identity is summarized in the ability of the person to recognize a place as a result of the uniqueness of its characteristics, and the environment depends on the identity of the use of special buildings and facades are distinct and this is because users always share and interact with such special activities.

So the environment has its own identity and personality not only when it has the ability to instill its visual distinction in people's memory, but also when it has the ability to make people recognize it through the facades of its buildings.

\section{Hence we realize that the identity of the buildings:}

- It is not just a product or something consistent and clear, it is a process that has many dimensions, a trace of civilization in various stages of histor,y and that is the locomotive of culture or identity of a civilization that is evident on the buildings themselves.

- Identity is the result of cultural heritage, it therefore can not be formed suddenly, but it develops in parallel to the development of modern raw materials and advanced technologyand this development is based on our vision to address our problems and existing and future buildings.

- Identity is intangible (18).

\section{Methods of evaluating and building facades Foreign spreads in terms of identity:}

Principles of evaluation: there are three main principles that should be taken into account in the evaluation, namely:

* Continuity: It can be expressed in a set of fixed values such as respect for the natural environment, unity in composition, respect for the human dimension and neighborliness, privacy protection to achieve communication between the interior design and the formation of the destinations of the building in simplicity and compatibility at all levels.

* Distinction: achieved through regional and environmental challenges as adaptation with the climate, the adoption of the principles of local architecture, the use of local building materials as well as the vocabulary of heritage in the internal and external architecture of the buildings, taking into account the integration of technology with the prevailing technology.

* Recognition: The perceptive to know the elements that integrate both the communication and excellence such as understand and absorb the local environment, the contemporary expression of traditional values and traditions, and re-use ideas and vocabularies of heritage architecture and integration of renewable curriculum and style heritage.

\section{Research results:}

1. The application of fine values on the outer spaces helps us to achieve successful designs.

2. To reach the bases and rules of urban coordination that are ideal for each space or building.

3. Benefit from our ancient Egyptian civilization and treatments that mimic the environmental and climatic nature of the various spaces.

4. Dependence on the environmental design, materials and natural resources available within the city.

5. Employment of modern technologies and technology is important not to get us in the departure and distance from identity.

6. To highlight the identity of the community and the impact of cultural heritage and civilization in the various designs of new communities. 


\section{Recommendations:}

1. Setting standards and requirements for urban coordination of economic housing in new societies.

2 - the need to link the interfaces of buildings and open areas.

3- Exploiting the available natural materials in the scope and employing them in design.

4 - the use of plants and plants that are in line with the natural environment of the city.

5 - To highlight the cultural identity and its role in the new communities and their impact in the design of distinctive features of different housing spaces.

\section{References:}

1. Mahmoud Mahmoud Fikri - urban furniture into the new urban cities - Master - Faculty of Fine Arts - Helwan University - 2001 - The R 75.

2. Basem Fadel Eid - Beauty of cities in Egypt (Problems and Solutions) - Conference on Art and Economics Faculty of Fine Arts - Minia University --2,016 - p. 2.

3. Mohammed Saber Abdul Hamid - interior architecture and its role in the development of curriculum to beautify the visual environment of the Egyptian city - art conference and Economics - Faculty of Fine Arts - Minia University --2,016 - p. 3.

4. Mahmoud Mahmoud Fikri - Urban furnishing of new cities - Master - Faculty of Fine Arts - Helwan University 2001

5-Maha Loay Mahmoud - the role of the interior architecture in shaping and building facades - art conference and Economics - Faculty of Fine Arts - Minia University --2,016 - p. 11.

6-Foundations and standards of urban coordination for open areas - the list of the National Agency for the Coordination of Urban - Egypt - First Edition - - 2010 p. 15.

7-Hala Barakat on - configuration elements from the surrounding environment and its relationship to the interior architecture - art conference and Economics - Faculty of Fine Arts - Minia University --2,016 - p. 5.

8-op - p. 2.

9- Reham Ismail Taha - morphology pathetic creativity in interior design - Master - Faculty of Fine Arts Alexandria University -, 2005

10-Jacoub, son of Joseph - planning and designing residential neighborhood - College of Architecture and Planning - King Saud University - 1429.

11-Ali Mehran Hisham - Elements of Urban Planning and Design --2,011

12- Abdullah bin Mohammad Aqeel - towards an integrated and sustainable housing solutions - King Fahd National Library for publication - I - - 2015 p. 109 edition.

13. principles and criteria of open coordination Urban areas - the list of the National Agency for the Coordination of Urban - Egypt - First Edition 2010 -.

14- http://amenagementa.blogspot.com.eg/2016/06/design.html 18/08/2016

15. Principles and criteria of open coordination Urban areas - the list of the National Agency for the Coordination of Urban - Egypt - First Edition 2010

16-Vkra Amer Muhammad Yunus - founded the design and implementation of gardens - Research Master supervision of Dr. / Nabil Rashid - Faculty of Fine Arts - Helwan University - 2012.

17-https: //old.uqu.edu.sa/page/ar/55862

18-Hilal Mohamed Ahmed - the identity crisis of contemporary architecture in the Egyptian city - Engineering Sciences Journal - number 722 - April 2004.

19. Maha Loay Mahmoud - the role of the interior architecture in shaping and building facades - art conference and Economics - Faculty of Fine Arts - Minia University -2016. 